\title{
Intervención en habilidades de formas y funciones comunicativas en un sujeto con Trastorno del Espectro Autista: Estudio de caso único
}

\author{
Intervention of form and communication function in a person with \\ Autism Spectrum Disorder: Case study
}

\author{
JOSÉ ANTONIO SAZO ÁVILA \\ Universidad de Talca. Talca, Chile \\ jsazo@utalca.cl
}

\section{RESUMEN}

El Trastorno del Espectro Autista (TEA) es un trastorno del desarrollo neurológico caracterizado por deficiencias persistentes en la comunicación e interacción social, así como por patrones restrictivos y repetitivos de comportamiento, intereses 0 actividades. La presente investigación expone un estudio de caso único de un niño receptor de una terapia, basada en el método de Análisis Aplicado de Conducta (o ABA, Applied Behavior Analysis en inglés), a fin de incrementar su conducta verbal. La terapia fue ejecutada y asistida por un fonoaudiólogo certificado. Al momento de su evaluación, el niño presentó escasa intención comunicativa y severos problemas de conducta. Tras la realización de 40 sesiones, se logró incrementar las formas y funciones comunicativas, así como modificar la conducta del paciente.

Palabras clave: Trastorno del Espectro Autista, Análisis Aplicado de Conducta, formas y funciones comunicativas. 


\section{ABSTRACT}

Autism Spectrum Disorder (ASD) is a neurodevelopmental disorder characterized by impairments in communication and social interaction, and restricted/repetitive behaviours patterns, interest or activities. This research show a case study for a boy that receives a therapy based in Applied Behaviour Analysis (ABA) to increase his verbal behaviour, realized by a speech and language therapyst certified in $A B A$. In the assessment, the patient show a low communicative intention and several behaviour problems. After 40 treatment sessions, the boy increase his forms and communicative functions, and he was achieved a behaviour modification.

Key words: Autism Spectrum Disorder, Applied Behaviour Analysis, form and communicative function.

\section{Introducción}

El Trastorno del Espectro Autista (TEA) es una condición que se describe en el DSM-V (Manual diagnóstico y estadístico de los trastornos mentales, 5ta edición) como un trastorno del desarrollo neurológico, caracterizado por una díada que comprende, por una parte, las deficiencias persistentes en la comunicación y en la interacción social en diversos contextos; y por otra, los patrones restrictivos y repetitivos del comportamiento, intereses 0 actividades (American Psychiatric Association, 2013). Este manual destaca las principales características vinculadas con las dificultades en la comunicación e interacción social, entre las que destacan: deficiencias en la reciprocidad socioemocional, fracaso o imposibilidad de mantener una conversación fluida y de iniciar o responder a interacciones sociales, anomalías del contacto visual y del lenguaje corporal, deficiencias en la comprensión y el uso de gestos, ausencia total de expresión facial y de comunicación no verbal, impedimentos para ajustar el comportamiento en diversos contextos sociales, dificultades para compartir juegos imaginativos, hacer amigos y hasta la ausencia de interés por otras personas (Zalaquett, Shönstedt, Angeli, Herrera \& Moyano, 2015).

El Análisis Aplicado de Conducta (ABA) consiste en una intervención o terapia conductual, basada en las teorías del aprendizaje para potenciar habilidades sociales. Por tal razón, es ampliamente utilizada para favorecer la funcionalidad y desarrollo de habilidades comunicativas de niños con TEA, con el fin de propiciar el aumento de las conductas adaptativas y la disminución de problemas 
conductuales para lograr una mayor participación del niño en los contextos en los que interactúa (Piñeros-Ortiz \& Toro-Herrera, 2012; Zalaquett, Shönstedt, Angeli, Herrera \& Moyano, 2015).

Por lo anteriormente señalado, a continuación, se presenta el estudio de caso de un estudiante a quien se le realizó una intervención basada en el Análisis Aplicado de Conducta (ABA), con el propósito de coadyuvar -con la participación de un fonoaudiólogo- a la disminución y superación de las diversas dificultades lingüísticas y comunicativas que se condicen con lo esperado por su diagnóstico de TEA.

\section{Método}

\section{Datos personales del paciente}

Este estudio de caso se basa en un niño de 10 años, sexo masculino, soltero, estudiante de una escuela especial y de un nivel socioeconómico medio alto, quien actualmente vive con sus padres y hermano mayor en la comuna de Talca. Los dos hijos de esta familia tienen un diagnóstico de Trastorno del Espectro Autista.

\section{Referencia y objetivos}

La madre del estudiante, este último en lo sucesivo se identificará con la inicial $\mathrm{V}$, acude al fonoaudiólogo puesto que refiere "que $\mathrm{V}$ mostró grandes avances con la terapia ABA en un centro especializado en Santiago, por lo que le gustaría darle continuidad al tratamiento". El objetivo de la intervención realizada fue determinar un perfil de formas y funciones comunicativas para poder potenciar su comunicación con su entorno escolar y familiar.

Al respecto, el niño asiste de forma irregular a la escuela especial, pues vive en una zona lejana al establecimiento, pero cuenta con apoyo profesional en su hogar de forma parcial y en varios momentos de la semana. El infante, también, logra comunicar algunas de sus intenciones protoimperativas (gestos para pedir algo 0 solicitar ayuda) con el uso de palabras aisladas, pero se evidencian conductas disruptivas, principalmente mantenidas por el acceso a la atención y como mecanismo para evadir o escapar de aquellas situaciones en las que se le solicita algo (tanto en la evaluación como a nivel cotidiano). 


\section{Evaluación inicial}

Las sesiones de evaluación se efectuaron en la casa de la familia, la cual contaba con una sala habilitada para la atención de las necesidades del estudiante. Se llevaron a cabo 4 sesiones de 1 hora cada una, aproximadamente. En la primera y última jornada, se realizaron entrevistas a la madre y se recabaron datos. Mientras que, en las sesiones 3 y 4 , se practicó la evaluación directa de las habilidades comunicativas y conductuales del niño.

La evaluación comunicativa de $\mathrm{V}$ se efectuó tras aplicar a su madre la Matriz de Comunicación (Rowland, 2016). Este instrumento permitió determinar las formas y funciones comunicativas del niño y entregó, además: un perfil de habilidades y la lista de destrezas comunicativas. Gracias a ello, se comprobó el nivel comunicativo de $\mathrm{V}$ y las funciones que pueden otorgarse a su comunicación. Se determinó, igualmente, el potencial de medir cambios según el rendimiento obtenido en la evaluación.

Cabe destacar que, la matriz se aplicó a la madre de $V$ mediante una entrevista guiada por el instrumento en una plataforma virtual, pero, previo a ello, se realizó una sesión de rapport con el niño para establecer, a través de la observación clínica, su edad lingüística. Se determinó que, pese a la edad cronológica de $\mathrm{V}$ (10,4 años), su rendimiento lingüístico y comunicativo frente a la observación clínica es inferior a lo esperado para un sujeto de 2 años, según el desarrollo típico del lenguaje. Como complemento, se practicó una evaluación directa de formas y funciones comunicativas, a través de juegos que fueran de interés para $\mathrm{V}$.

Finalmente, se realizó una evaluación conductual con la aplicación de la herramienta Functional Assessment Screening Tool (FAST) frente a la observación directa de las conductas de $\mathrm{V}$.

\section{Resultados}

En una entrevista semiestructurada, la madre señala que el niño alcanzó un desarrollo típico hasta los 3 años de edad. A partir de ese momento, ella notó un retroceso en las habilidades de V, por lo que comenzó a consultar diversos profesionales de Talca. Después de un tiempo, la familia se radicó en Santiago, con el propósito de brindar a $V$ un apoyo especializado que le permitiera desarrollar habilidades comunicativas y conductuales adaptadas a él. Ya en Santiago, V 
ingresó a CERIL Las Condes, donde recibió terapia ABA en jornada completa y, frente a la cual, logró un desarrollo del lenguaje que le permite comunicar algunos de sus deseos y peticiones a nivel familiar.

Tiempo después, debido a motivos familiares, la familia regresó a Talca. Allí, se encontraron con una limitada cantidad de profesionales especializados en la terapia ABA. En consecuencia, y para apoyar el desempeño social de su hijo, los padres de $V$ acudieron a un colegio especial que estuviese en capacidad de dar respuesta a las necesidades educativas del niño. En paralelo, $V$ recibe terapia de diversos profesionales de forma particular y domiciliaria (terapeuta ocupacional, fonoaudiólogo, educador diferencial), pues sus padres requerían apoyo, tanto para el manejo conductual del niño como para que lograra comunicarse de forma funcional con su familia y en el colegio.

Cabe acotar que, $V$ ha logrado conservar algunas de las habilidades adquiridas en los programas ABA realizados en Santiago, pero, según el equipo multiprofesional que sigue trabajando con él (y en consonancia a lo reportado por la familia), sus dificultades con la conducta adaptativa complican y obstaculizan los aprendizajes que él puede consolidar y desarrollar.

Frente a la evaluación de sus formas y funciones comunicativas, $V$ presenta un rendimiento que se ve mermado por su impedimento para ejecutar algunas de las órdenes que se le solicitan, puesto que presenta alteraciones a nivel conductual que limitan en un alto nivel su desempeño en cuanto a la comunicación.

Según los resultados de la aplicación del cuestionario FAST, V posee dificultades severas a nivel conductual, las cuales se manifiestan frente a antecedentes cotidianos (peticiones de acciones como sentarse, responder a preguntas, realizar alguna tarea específica). Estas dificultades se mantienen, principalmente, porque $\mathrm{V}$ quiere escapar de lo que se le solicita o porque quiere acceder a la atención de algún adulto $o$ interlocutor.

\section{Integración de resultados}

La hipótesis que subyace a este caso, es que $\mathrm{V}$ logre comunicarse de forma funcional con su familia y entorno escolar, con el uso de frases comunicativas y el apoyo de imágenes. 
Lo anterior se evidenció con la evaluación realizada, pues $V$ poseía un perfil de habilidades comunicativas emergentes, que, de ser trabajadas y potenciadas de forma intensiva y estructurada, podrían consolidarse como un sistema de comunicación funcional y contextualizada que le permitiría expresar algunas intenciones comunicativas imperativas, declarativas y de rutina social de forma convencional.

\section{Intervención}

Con la utilización de programas basados en el Análisis Aplicado de Conducta $(A B A)$, se pretendió incrementar la conducta verbal de V, con el desarrollo de habilidades que le permitieran comunicarse funcionalmente con su entorno familiar y escolar.

El aspecto que se intervino tuvo relación con las formas comunicativas, puesto que $V$ había experimentado un descenso en su rendimiento con respecto al uso de palabras y frases para pedir y declarar, valiéndose para ello, principalmente, de pataletas y de la instrumentalización de su interlocutor.

Según lo reportado por la madre, y con relación a su motivo de consulta, se seleccionó el método $A B A$, ya que se había hecho referencia sobre la aplicación en $\mathrm{V}$ de una intervención intensiva de ese método durante su permanencia en Santiago, la cual le permitió comunicarse con las habilidades que demostró en la evaluación.

El proceso de intervención se llevó a cabo en 40 sesiones (grabadas en su totalidad), que fueron ejecutadas durante 5 meses en el domicilio particular del niño, en una habitación especialmente acondicionada, que contaba con una baja tasa de agentes distractores. La frecuencia de las sesiones fue de 2 veces por semana, durante 1 hora cada una. Estas se estructuraron con apoyo de un tablero de anticipación y se segmentaron en bloques de trabajo de aproximadamente 5 minutos cada uno, con recreos intermedios que duraron desde 3 hasta 1 minutos, según el progreso evidenciado en el rendimiento atencional de V. Las actividades llevadas a cabo estuvieron basadas en el entrenamiento directo de las conductas verbales que se trabajaron. En tal sentido, se realizaron programas de "sustantivos", "lugares", "categorías semánticas" y "respuestas a preguntas". 
De forma transversal, se practicó una intervención basada en la modificación de conducta, la cual se ejecutó de forma paralela, principalmente, mediante el apoyo físico total o parcial del niño.

Es de destacar que, una de las principales dificultades para evidenciar mayores progresos en el tratamiento fue la frecuencia de las sesiones, puesto que la terapia ABA debe desarrollarse de forma intensiva, en lo posible diariamente.

\section{Valoración de la intervención}

La medición de los resultados de la intervención se efectuó en forma constante, mediante pautas de registros, realizadas en cada sesión y basadas en la cantidad de estímulos trabajados en V, así como en sus respuestas a lo solicitado (a nivel espontáneo, con andamiaje o a la repetición).

Con relación a los resultados obtenidos en las sesiones, se puede señalar que el niño consiguió realizar lo solicitado a nivel conductual con apoyo físico solo en las extremidades inferiores. Por otro lado, logró utilizar las manos para realizar algunas tareas de categorización semántica de forma adaptada. En cuanto a las funciones de sus alteraciones conductuales, hay que señalar que el entrenamiento permitió que $\mathrm{V}$ disminuyera sus conductas mantenidas por atención y escape, pero no de forma total.

En cuanto a las formas y funciones comunicativas, $V$ logró incrementar su vocabulario activo de sustantivos en 50 palabras a nivel espontáneo. El resultado más relevante fue que consolidó la petición de objetos o acciones de forma oral, utilizando mayormente palabras aisladas con su interlocutor.

Algunos de los cambios referidos anteriormente pudieron evidenciarse en el colegio, lo cual ratifica y le da valor a uno de los criterios más relevantes para quienes realizan terapia $A B A$, puesto que las conductas verbales 0 adaptadas alcanzadas deben generalizarse a los contextos frecuentes de los beneficiarios.

Posteriormente, la terapia fue detenida por motivos personales de la familia. En consecuencia, se sugirió realizar un seguimiento de los logros alcanzados por el estudiante tanto a nivel familiar como escolar desde el establecimiento educativo, a fin de apoyar el proceso de enseñanza-aprendizaje que $\mathrm{V}$ pueda desarrollar en su ámbito escolar. En este sentido y con tal fin, se tiene contacto frecuente con 
el colegio y existe disponibilidad para poder guiar el logro del programa educativo individual que la institución se plantea para trabajar con el beneficiario.

\section{Discusión y conclusiones}

$V$ es un estudiante de una escuela especial, de 10 años y 4 meses de edad, diagnosticado con TEA. En cuanto a sus habilidades, utiliza algunas palabras aisladas y emergentes frases de 2 palabras (formas comunicativas) para comunicarse con su familia (función comunicativa). Dentro de sus principales dificultades, se encuentran la escasa intención comunicativa declarativa e imperativa, así como alteraciones severas a nivel conductual.

La intervención de estos aspectos se realizó en base a una terapia de modificación conductual basada en ABA, cuyo objetivo fue incrementar la conducta verbal de $\mathrm{V}$, potenciando el desarrollo de habilidades que le permitieran comunicarse de forma funcional con su entorno familiar y escolar.

De los resultados de la terapia, se desprende que $\mathrm{V}$ logró incrementar su vocabulario activo de sustantivos en 50 palabras a nivel espontáneo. Asimismo, consolidó la petición de objetos 0 acciones de forma oral, utilizando mayormente palabras aisladas con su interlocutor.

En resumen, el incremento de la conducta verbal en $\mathrm{V}$ le ha permitido poder comunicarse de forma efectiva con su entorno escolar y social. Las futuras intervenciones en el paciente deberían enfocarse en potenciar la comunicación a nivel convencional y desarrollar conductas adaptativas que le faciliten incluirse de forma integral en la sociedad.

Por otro lado, más allá de que existen otras propuestas de intervención efectivas para niños con TEA (Piñeros-Ortiz \& Toro-Herrear, 2012), se considera la terapia ABA como una buena propuesta de intervención para el caso de las dificultades comunicativas que posee $\mathrm{V}$, puesto que se alcanzaron las metas propuestas en el inicio de la intervención y se aumentaron sus posibilidades de interacción con su entorno, tanto escolar como familiar. En general, se sugiere generar intervenciones tempranas en los niños con TEA que involucren el contexto familiar, educativo y comunitario, con el fin de tener un buen pronóstico funcional a lo largo del ciclo vital de los estudiantes con TEA (Zalaquett et al., 2015). 


\section{Notas de autor}

La información contenida en el presente estudio de caso, ha sido autorizada mediante la firma de un consentimiento/asentimiento otorgado por la madre del niño. Este estudio de caso fue presentando en el contexto del Magíster en Educación Especial y Psicopedagogía de la Universidad Católica del Maule.

\section{REFERENCIAS BIBLIOGRÁFICAS}

AGUADO, G.A. \& GÁNDARA, C.C. (2013). Evaluación de la comunicación y el lenguaje en el Trastorno del Espectro Autista. Lima: Ediciones Libro Amigo EIRL.

AMERICAN PSYCHIATRIC ASSOCIATION. (2013). Diagnostic and statistical manual of mental disorders (5th edition). Arlington, VA: American Psychiatric Publishing.

MINISTERIO DE SALUD DE CHILE (2011). Guía de práctica clínica: Detección y diagnóstico oportuno de los Trastornos del Espectro Autista. Ministerio de Salud: Departamento de Discapacidad y Rehabilitación. Recuperado de http://web. minsal.cl/portal/url/item/bd81e3a09ab6c3cee040010164012ac2.pdf

MILTENBERGUER, R. G. (2013). Modificación de conducta. Madrid: Editorial Pirámide.

PIÑEROS-ORTIZ, S.E. \& TORO-HERRERA, S.M. (2012). "Conceptos generales sobre ABA en niños con Trastorno del Espectro Autista". Revista Facultad de Medicina, 60: 60-66.

XIANG, T.T.; MIN LOW, H.; HWEE, N.K.; KEONG, A.C. \& WAH LEE, L. (2014). "Prevalence, Diagnosis, Treatment and Research oh Autism Spectrum Disorders (ASD) in Singapore and Malaysia". International Journal of Special Education, 29 (3), 82-92.

ZALAQUETT, D.; SHÖNSTEDT, M.; ANGELI, M.; HERRERA, C. \& MOYANO, A. (2015). "Fundamentos de la intervención temprana en niños con trastornos del espectro autista". Revista Chilena de Pediatría, 6(2): 126-131. 